\title{
Nanodeserts: A Conjecture in Nanotechnology to Enhance Quasi-Photosynthetic $\mathrm{CO}_{2}$ Absorption
}

\author{
Wenfeng Wang, ${ }^{1}$ Xi Chen, ${ }^{1}$ Yifan Zhang, ${ }^{2}$ Jianjun Yu, ${ }^{3}$ Tianyi Ma, ${ }^{4}$ Zhihan Lv, ${ }^{5}$ \\ Jing Zhang, ${ }^{6}$ Fanyu Zeng, ${ }^{7}$ and Hui Zou ${ }^{8}$ \\ ${ }^{1}$ State Key Laboratory of Desert and Oasis Ecology, Xinjiang Institute of Ecology and Geography, \\ Chinese Academy of Sciences, Urumqi 830011, China \\ ${ }^{2}$ Department of Chemistry, Inha University, 100 Inharo, Incheon 402-751, Republic of Korea \\ ${ }^{3}$ Environmental Change Institute, University of Oxford, Oxford OX1 3QY, UK \\ ${ }^{4}$ School of Chemical Engineering, University of Adelaide, Adelaide, SA 5005, Australia \\ ${ }^{5}$ High Performance Computing Center, Shenzhen Institutes of Advanced Technology, Chinese Academy of Sciences, \\ Shenzhen 518055, China \\ ${ }^{6}$ College of Energy and Mechanical Engineering, Shanghai University of Electric Power, Shanghai 200090, China \\ ${ }^{7}$ Center for Robotics, University of Electronic Science and Technology of China, Chengdu 610054, China \\ ${ }^{8}$ Department of Computer Science and Technology, Huaqiao University, Xiamen 361021, China
}

Correspondence should be addressed to Xi Chen; chenxi@ms.xjb.ac.cn and Tianyi Ma; matianyichem@gmail.com

Received 27 April 2016; Revised 22 May 2016; Accepted 5 June 2016

Academic Editor: Yiwen Li

Copyright (C) 2016 Wenfeng Wang et al. This is an open access article distributed under the Creative Commons Attribution License, which permits unrestricted use, distribution, and reproduction in any medium, provided the original work is properly cited.

This paper advances "nanodeserts" as a conjecture on the possibility of developing the hierarchical structured polymeric nanomaterials for enhancing abiotic $\mathrm{CO}_{2}$ fixation in the soil-groundwater system beneath deserts (termed as quasi-photosynthetic $\mathrm{CO}_{2}$ absorption). Arid and semiarid deserts ecosystems approximately characterize one-third of the Earth's land surface but play an unsung role in the carbon cycling, considering the huge potentials of such $\mathrm{CO}_{2}$ absorption to expand insights to the longsought missing $\mathrm{CO}_{2}$ sink and the naturally unneglectable turbulence in temperature sensitivities of soil respiration it produced. "Nanodeserts" as a reconciled concept not only indicate a conjecture in nanotechnology to enhance quasi-photosynthetic $\mathrm{CO}_{2}$ absorption, but also aim to present to the desert researchers a better understanding of the footprints of abiotic $\mathrm{CO}_{2}$ transport, conversion, and assignment in the soil-groundwater system beneath deserts. Meanwhile, nanodeserts allow a stable temperature sensitivity of soil respiration in deserts by largely reducing the $\mathrm{CO}_{2}$ release above the deserts surface and highlighting the abiotic $\mathrm{CO}_{2}$ fixation beneath deserts. This may be no longer a novelty in the future.

\section{Introduction}

Attempts to account for the global atmospheric $\mathrm{CO}_{2}$ fluxes by quantifying $\mathrm{CO}_{2}$ sources and sinks have provided evidence of an unneglectable missing $\mathrm{CO}_{2}$ sink [1-3]. There are numerous studies that claimed to find the "missing sink," but none of those claims has been widely accepted $[4,5]$. Recently, the reports of carbon uptake by arid and semiarid desert ecosystems revealed rates of carbon uptake in many forests (i.e., the $\mathrm{CO}_{2}$ absorption rate is up to the photosynthetic absorption level) and focused research attention on arid and semiarid deserts ecosystems as the location of the longsought "missing $\mathrm{CO}_{2}$ sink" [6-13], which was termed as quasi-photosynthetic $\mathrm{CO}_{2}$ absorption [6]. There is strong evidence suggesting that absorbed $\mathrm{CO}_{2}$ significantly contributes to the total soil $\mathrm{CO}_{2}$ flux [7-10]. Arid and semiarid deserts ecosystems approximately characterize one-third of the Earth's land surface and play unsung role in the carbon cycling [9]. But where the absorbed $\mathrm{CO}_{2}$ has gone remains undetermined [11, 12]. A latest publication claimed that such absorption can be attributed to geochemical $\mathrm{CO}_{2}$ dissolution in saline aquifers beneath deserts [9], but the intensity of 
$\mathrm{CO}_{2}$ dissolution and absorption and the extent to which it modulates the global $\mathrm{C}$ balance are still a matter of controversy $[9,13,14]$.

Differential, difference, and dynamic equations are used for quantitative analysis in the engineering and natural sciences [15-18]. This suggests us trying to develop some differential equations to describe the dynamics of $\mathrm{CO}_{2}$ dissolution and absorption beneath deserts. Since absorbed $\mathrm{CO}_{2}$ is largely dissolved in saline aquifers $[9,10]$, the dynamic equations for groundwater dissolved in $\mathrm{CO}_{2}$ (DIC) are representative for both dissolution and absorption. Before this modeling work, the possible difficulties and uncertainties must be theoretically analyzed. Particularly, the quasi-photosynthetic $\mathrm{CO}_{2}$ absorption as a component of soil respiration in deserts is abound to produce turbulence in temperature sensitivities of soil respiration. The first estimate of the absorption intensity is very promising [12], but a subsequent challenge is how to reduce the $\mathrm{CO}_{2}$ release above the deserts surface and enhance the abiotic $\mathrm{CO}_{2}$ fixation beneath deserts. Otherwise, the abiotic $\mathrm{CO}_{2}$ fixation cannot be utilized [19-22] Hierarchical structured polymeric materials, benefitting from nanotechnology enhancement, exhibited superior adsorption selectivity, high adsorption capacity, water tolerance, and low energy consumption with respect to physisorption, holding great promise for $\mathrm{CO}_{2}$ capture, and the capture can consequently, maybe, employed in the future utilization and enhancement of quasi-photosynthetic $\mathrm{CO}_{2}$ absorption beneath deserts. Considering the rapid development of nanotechnology and the wide applications hierarchical structured polymeric materials $[23,24]$, it can be conjectured that there are opportunities for the innovative design of self-assembling polymeric materials for the separation of aboveground $\mathrm{CO}_{2}$ release and underground $\mathrm{CO}_{2}$ fixation.

This paper hypothesizes that in the future it is possible to develop some hierarchical structured polymeric materials to enhance quasi-photosynthetic $\mathrm{CO}_{2}$ absorption in deserts and advance "nanodeserts" as a conjecture in nanotechnology for modulating abiotic $\mathrm{CO}_{2}$ fixation in the soil-groundwater system. To illustrate the necessity for introducing this concept, the influences of quasi-photosynthetic $\mathrm{CO}_{2}$ absorption on temperature sensitivities of soil respiration are explicitly analyzed. A perspective Riccati Equation for the quasiphotosynthetic $\mathrm{CO}_{2}$ absorption in the soil-groundwater system is established, providing that the hierarchical structured polymeric materials physically reduce the soil surface $\mathrm{CO}_{2}$ release and enhance the abiotic $\mathrm{CO}_{2}$ fixation beneath nanodeserts and allow a stable temperature sensitivity of soil respiration in deserts and a reliable quantification of $\mathrm{CO}_{2}$ absorption intensity on regional and global nanodeserts.

\section{Materials and Methods}

2.1. Data Sources. "Nanodeserts" are a conjecture on the possibility of developing hierarchical structured polymeric materials to enhance abiotic $\mathrm{CO}_{2}$ fixation in the soilgroundwater system, where nanoporous materials are supposed to be able to largely reduce the $\mathrm{CO}_{2}$ release from the surface of the soil-groundwater system and enhance the quasi-photosynthetic $\mathrm{CO}_{2}$ absorption beneath nanodeserts.

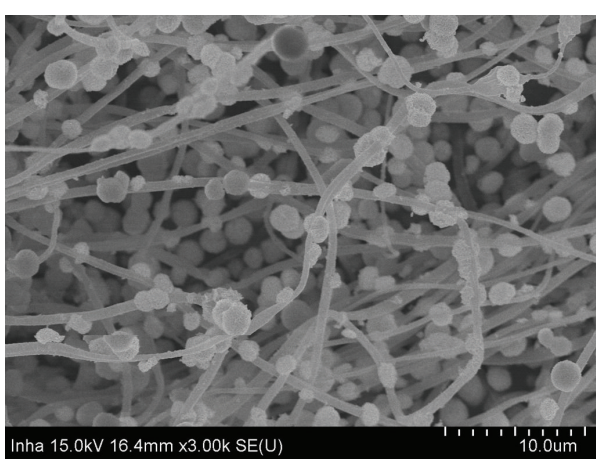

FIGURE 1: SEM image of polyethylenimine (PEI) nanofibers, loading with $\mathrm{BiOCl}$ nanoparticles.

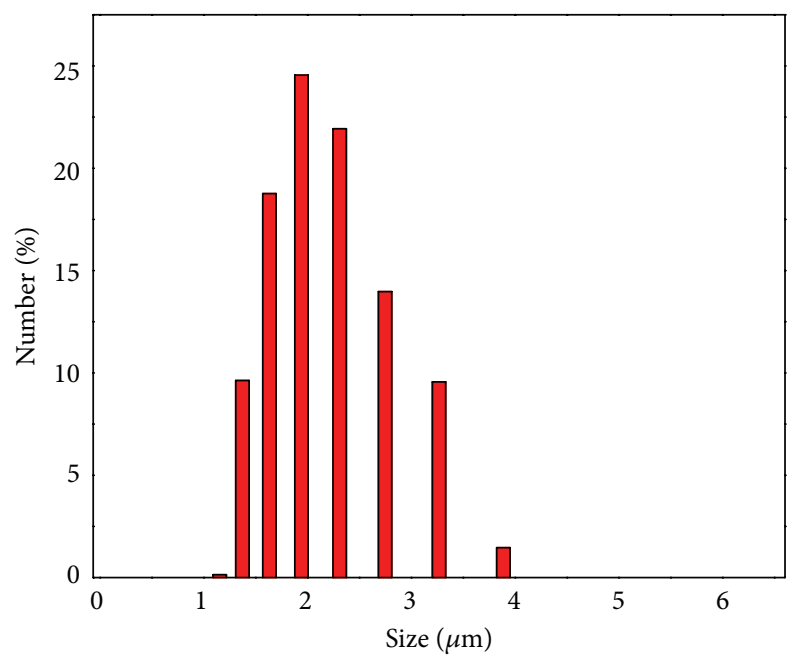

FIGURE 2: SEM image of polyethylenimine (PEI) nanofibers, loading with $\mathrm{BiOCl}$ nanoparticles.

As a particular example, the higher-resolution SEM images of polyethylenimine nanofibers (Figures 1, 2, and 3; loading with $\mathrm{BiOCl}$ nanoparticles) were collected. The morphology was evaluated via scanning electron microscopy (SEM, Model SU8010, Hitachi Co., Ltd.).

To highlight the necessity for this conjecture, the potential influences of the quasi-photosynthetic $\mathrm{CO}_{2}$ absorption on the temperature sensitivities $\left(Q_{10}\right)$ of soil respiration $\left(R_{s}\right)$ are basically analyzed. This work is based on the $R_{s}$ values (both positive and negative values) and the corresponding $\theta_{s}, T_{a}$, and $T_{s}$ values collected from some previous publications, with the analysis of $Q_{10}$ of $R_{s}$ to soil temperature at $5 \mathrm{~cm}$ depths $\left(T_{s}\right)$ and air temperatures at $10 \mathrm{~cm}$ above the soil surface $\left(T_{a}\right)$ at typical ecosystems along a gradient of soil alkalinity at $5 \mathrm{~cm}$ depths within the Manas River Basin $[6,12,25]$.

The Manas River Basin is located at the southern periphery of the Gurbantunggut Desert and in the hinterland of the Eurasian continent. Soils in this inland river basin bear typical physical and chemical characteristics, which are resulting from the soil water and soil salt transport during regional hydrological processes [26]. Almost $10 \times 10^{6} \mathrm{~km}^{2}$ of the hinterland of the Eurasian continent is arid and 


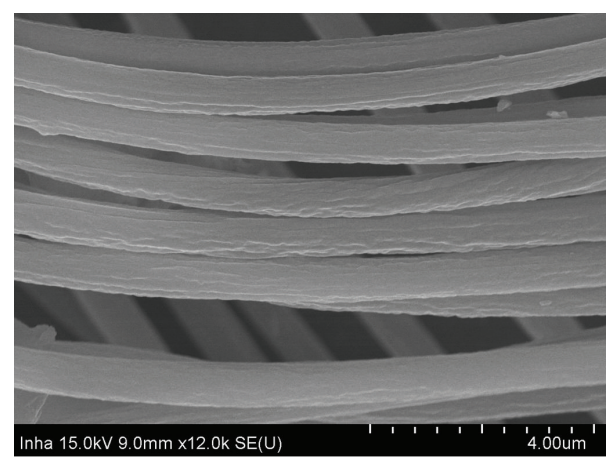

FIGURE 3: The SEM image of polyethylenimine (PEI) nanofibers.

semiarid deserts ecosystems. The inland rivers carried large quantities of salt into the Eurasian continent, resulting in strong, complicated ecological responses and forming the world largest desert-oasis compound system, which allows us to carry experiments at typical saline desert sites and typical cropped farmland sites, respectively.

2.2. Calculation and Modeling. The size of the nanoparticles was statistically analyzed utilizing the DLS measurement (Figure 2). $Q_{10}$ values used in the analysis were calculated using the following formula (for consistence, the negative values of $R_{s}$ were not included in calculations of $Q_{10}$ ), using the simple model of $R_{s}$ (the derivative of the exponential chemical reaction-temperature equation originally developed by Van't Hoff) [27]:

$$
\frac{R_{s T}}{R_{s T_{0}}}=Q_{10}^{\left(T-T_{0}\right) / 10},
$$

where $R_{s T}$ and $R_{s T_{0}}$ are the $R_{s}$ rates $\left(\mu \mathrm{mol} \mathrm{CO} \mathrm{m}^{-2} \mathrm{~s}^{-1}\right)$ at $T$ and $T_{0}$, respectively.

Developing hierarchical structured polymeric materials to enhance quasi-photosynthetic $\mathrm{CO}_{2}$ absorption beneath nanodeserts is very urgent and might draw much attention in the future. Hypothesizing that such nanoporous carbon materials were finally synthesized, the performance of $\mathrm{CO}_{2}$ absorption, conversion, and assignment beneath nanodeserts would be further studied. Therefore, it is also necessary to present a preliminary discussion of the coming modeling work when this interesting and innovative conjecture was demonstrated [28]. Riccati Equation is traditionally serving for the theory of transonic gas-dynamic flows and is hence employed in the present study to illustrate how to model $\mathrm{CO}_{2}$ footprints beneath nanodeserts.

\section{The Major Results}

3.1. Necessity to Introduce "Nanodeserts". The necessity to introduce "nanodeserts" depends on whether wide utilization of quasi-photosynthetic $\mathrm{CO}_{2}$ absorption is feasible and reliable quantification of its overall importance is possible. Since it has been demonstrated that the current soil-groundwater system in arid and semiarid deserts ecosystems contributes both positive and negative $\mathrm{CO}_{2}$ fluxes and the magnitudes of these two fluxes components are almost the same [9-13], wide utilization of quasi-photosynthetic $\mathrm{CO}_{2}$ absorption is infeasible unless nanodeserts are introduced. Considering the rapid development of nanotechnology and its applications in $\mathrm{CO}_{2}$ capture and storage technology [29-36], nanodeserts as an emerging technology may be no longer a novelty in the future since deserts are attracting more and more interest in the increasingly urbanized world [37-40]. Because the wide range of nanomaterials and the particle sizes provides optional sizes of nanoparticles in the fabrication of nanomaterials (Figure 1), we can conjecture that there is an optimal size of nanoparticles to largely reduce $\mathrm{CO}_{2}$ release and meanwhile enhance the abiotic $\mathrm{CO}_{2}$ dissolution and fixation beneath nanodeserts.

The turbulence in $Q_{10}$ values is evident. Quasi-photosynthetic $\mathrm{CO}_{2}$ absorption was demonstrated to have significant influences on temperature sensitivities $\left(Q_{10}\right)$ of soil respiration $\left(R_{s}\right)$, which highlight the necessity to introduce "nanodeserts." Using positive $R_{s}$ values, $Q_{10}$ was calculated by the relative change in $R_{s}$ with each $10^{\circ} \mathrm{C}$ increase of $T_{s}$ in the saline desert and cropped farmland largely fell into $[1,2]$ and $[1,3]$, respectively, while calculated $Q_{10}$ by the relative change in $R_{s}$ with $10^{\circ} \mathrm{C}$ increases of $T_{a}$ largely fell into $[3,13]$ and $[2,4]$, respectively. The mean $Q_{10}$ value of $R_{s}$ to $T_{a}\left(Q_{10}\right.$ $=4.88)$ was almost three times the mean $Q_{10}$ value of $R_{s}$ to $T_{s}$ $\left(Q_{10}=1.66\right)$, implying that $R_{s}$ in the alkaline land was much more sensitive to $T_{a}$ than to $T_{s}$. The mean $Q_{10}$ value of $R_{s}$ to $T_{a}$ in the desert $\left(Q_{10}=6.83\right)$ was more than the mean $Q_{10}$ value of $R_{s}$ to $T_{a}$ in the farmland $\left(Q_{10}=2.95\right)$, implying that $R_{s}$ in the desert was more sensitive to $T_{a}$ than $R_{s}$ in the farmland. However, $R_{s}$ in the desert was less sensitive to $T_{s}$ (with the mean $Q_{10}=1.33$ ) than $R_{s}$ in the farmland (with the mean $\left.Q_{10}=1.98\right)$. Although those negative $R_{s}$ were excluded and only the positive values were used in the calculations of $Q_{10}$, their significant influences on the response of $R_{s}$ to $T_{s}$ still existed. Additionally, the calculated $Q_{10}$ uniformly decreased with temperature $\left(T=T_{s}\right.$ or $\left.T_{a}\right)$ at both sites. This indicated that the variations of $Q_{10}$ with temperature in alkaline lands were not different from that in other terrestrial ecosystems (Figure 4).

Such turbulence in $Q_{10}$ values majorly resulted from the alternatively appearing positive and negative $R_{s}$. It is therefore essentially necessary to introduce "nanodeserts" as a conjecture on the possibility of developing hierarchical structured polymeric materials to largely reduce the $\mathrm{CO}_{2}$ release from the surface of the soil-groundwater system and enhance the quasi-photosynthetic $\mathrm{CO}_{2}$ absorption beneath nanodeserts by nanoporous modulation of the abiotic $\mathrm{CO}_{2}$ fixation in the soil-groundwater system. A series of polymers are suitable for nanodeserts working in the future and the chemical structure of polymer specially used for illustration here. The chemisorption of $\mathrm{CO}_{2}$ via amine-based materials is an efficient approach to reduce the greenhouse gas emission. In particular, polyethylenimine (PEI) impregnated materials exhibit superior adsorption selectivity, high adsorption capacity, water tolerance, and low energy consumption with respect to physisorption, holding great promise for $\mathrm{CO}_{2}$ capture (Figure 5). 


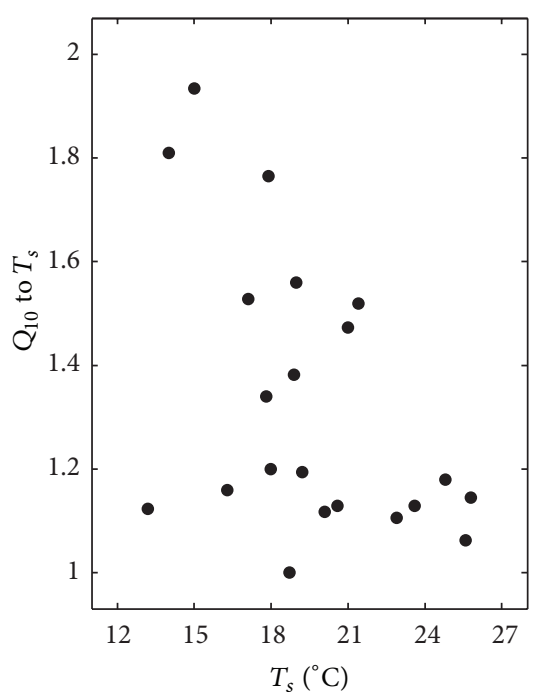

(a)

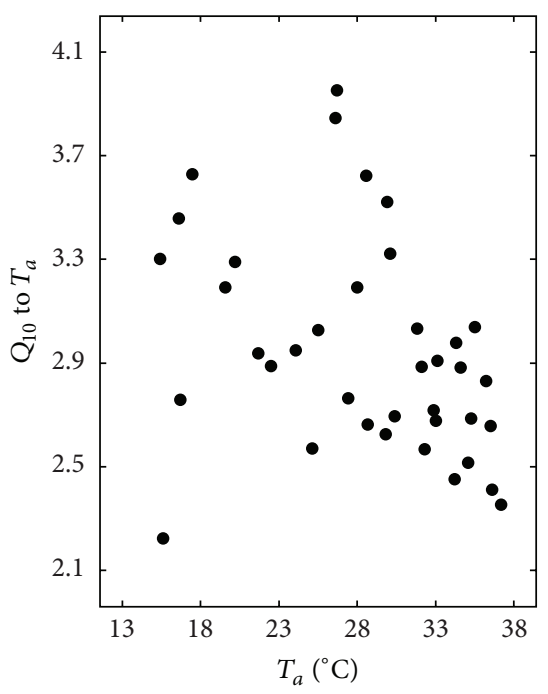

(d)

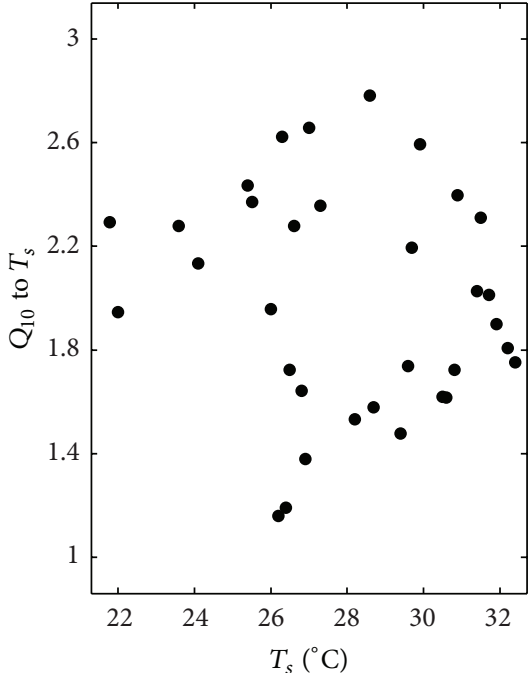

(b)

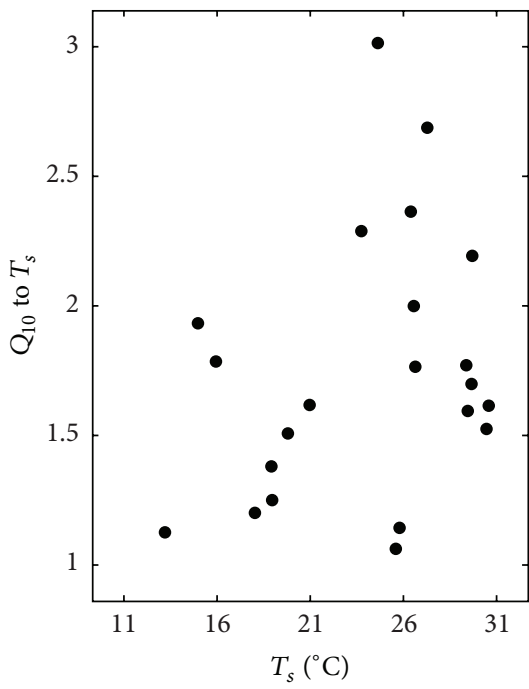

(e)

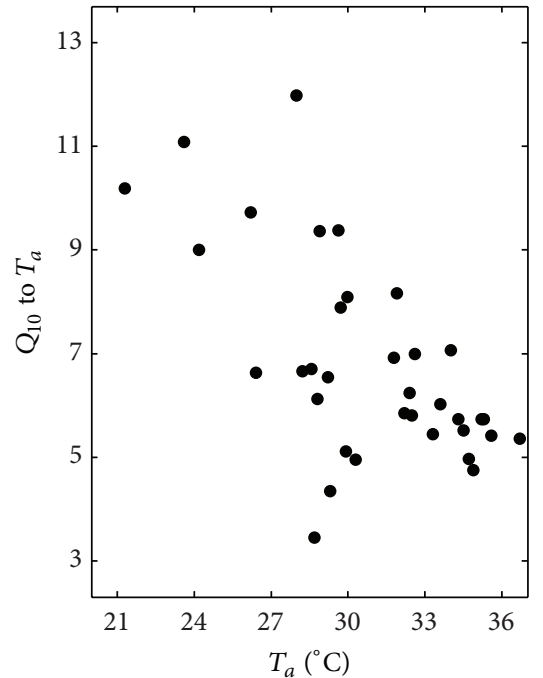

(c)

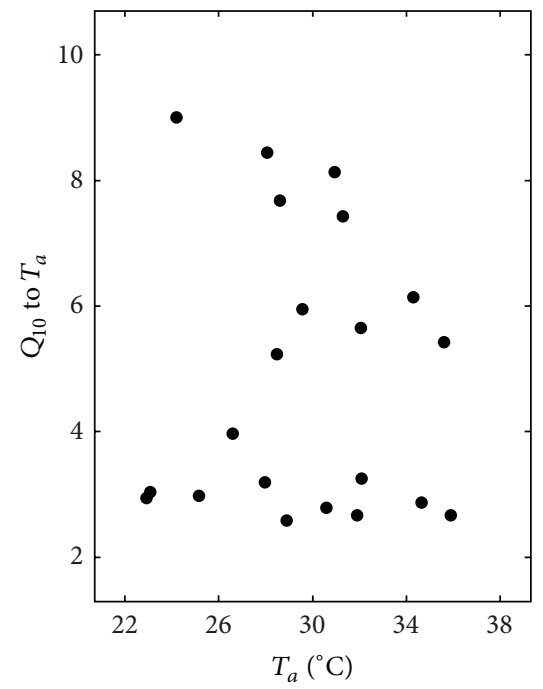

(f)

Figure 4: Responses of the temperature sensitivity $\left(Q_{10}\right)$ to soil temperature at $5 \mathrm{~cm}$ depth $\left(T_{s}\right)$ and air temperature $10 \mathrm{~cm}$ above the soil surface $\left(T_{a}\right)$ in saline desert $(\mathrm{a}, \mathrm{c})$ and cropped farmland $(\mathrm{b}, \mathrm{d})$ and the responses of $Q_{10}$ to $T_{s}$ and $T_{a}$ when taking the saline desert and cropped farmland data together $(e, f)$.<smiles>CCN(CCN)CCNCCN(CCNCCN)CCN(CCN)CCN</smiles>

FIGURE 5: The chemical structure of polyethylenimine (PEI).

3.2. $\mathrm{CO}_{2}$ Footprints beneath Nanodeserts. Nanodeserts equipped with hierarchical structured polymeric materials can largely reduce the $\mathrm{CO}_{2}$ release from the surface of the soil-groundwater system and enhance the quasiphotosynthetic $\mathrm{CO}_{2}$ absorption beneath nanodeserts by nanoporous modulation of the abiotic $\mathrm{CO}_{2}$ fixation in the soil-groundwater system, which not only allows a stable temperature sensitivity $\left(Q_{10}\right)$ beneath $\mathrm{CO}_{2}$ absorption and dissolution in the soil-groundwater system, but also makes it easy for deserts researchers to predict the $\mathrm{CO}_{2}$ footprints beneath nanodeserts. Despite the wide applications of hierarchical structured polymers [41-46], they are slightly associated to modulate the carbon cycle in deserts and so it is difficult to provide the quantification data of polymer used for $\mathrm{CO}_{2}$ absorption and the efficiency of $\mathrm{CO}_{2}$ fixation beneath deserts. This is really a challenge. At current stage, we can only present a first approach to quantification data of polymer used for $\mathrm{CO}_{2}$ absorption and the efficiency of $\mathrm{CO}_{2}$ fixation beneath deserts based on the parameter of $\mathrm{CO}_{2}$ 


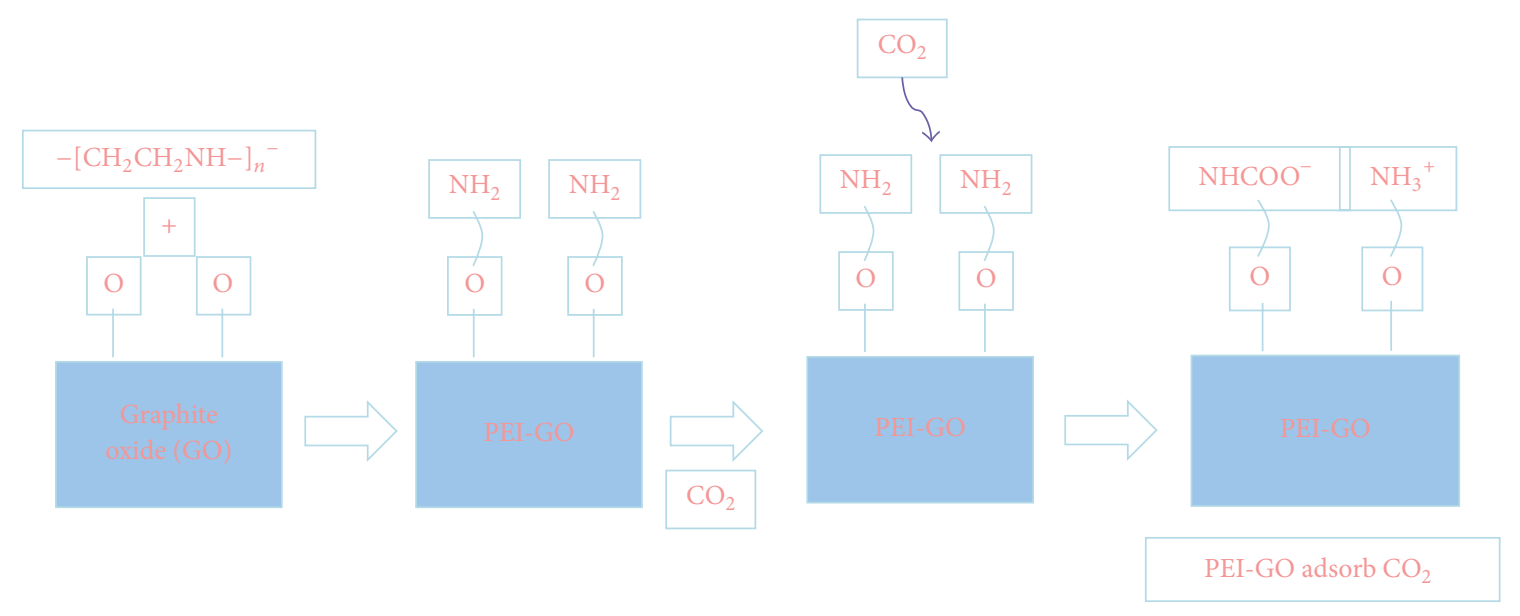

FIGURE 6: Effect of $\mathrm{CO}_{2}$ capture of impregnated-graphite oxide by polyethylenimine.

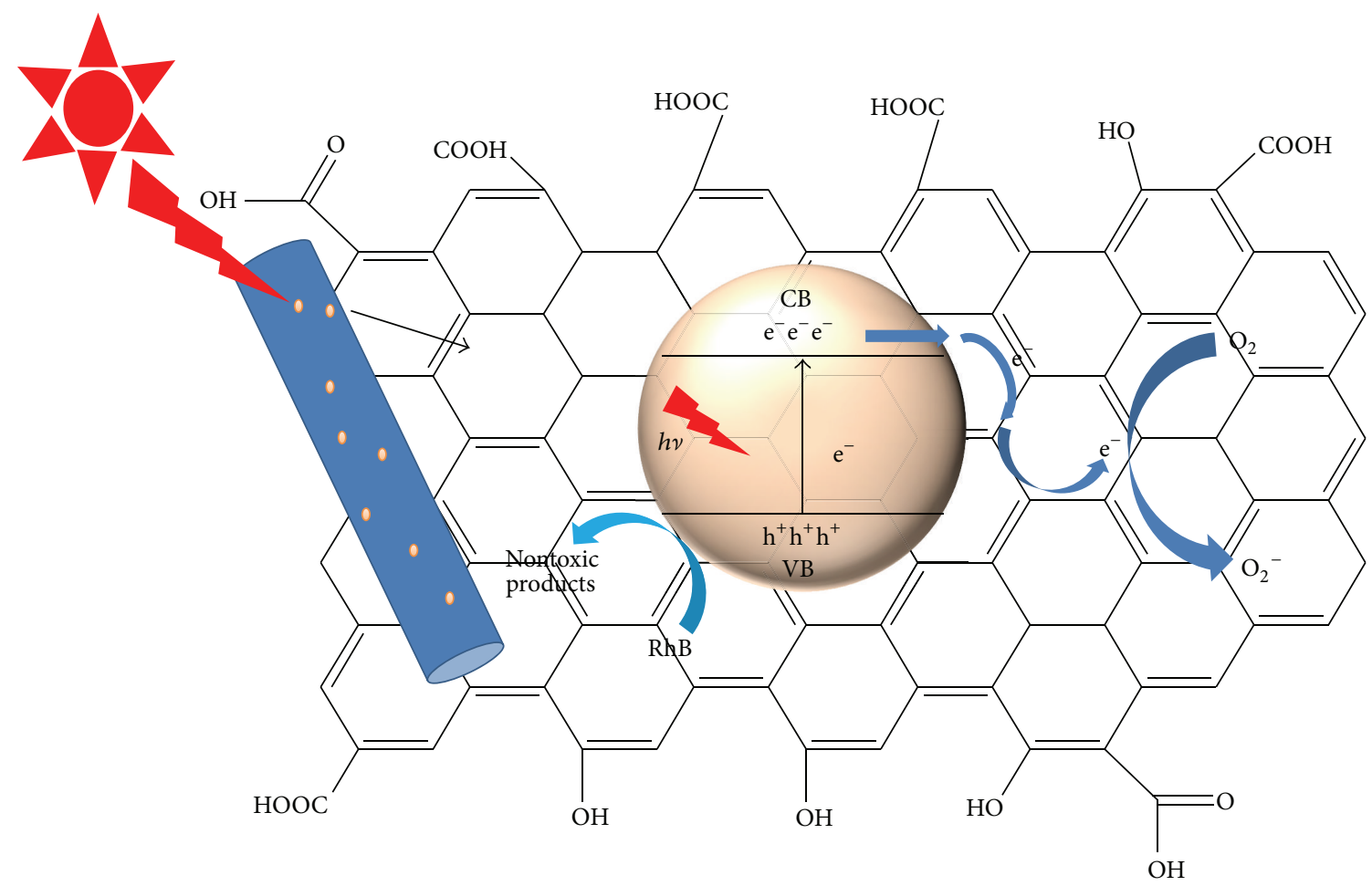

Figure 7: A conceptual mechanism about the graphene oxide/BiOCl heterostructured nanofibers (the specified example in this study) for visible-light photocatalytic enhancements of $\mathrm{CO}_{2}$ fixation.

content, power of visible-light for photocatalysis they used for calculation and modeling. Here is a specific example to explain how to carry out and evaluate the $\mathrm{CO}_{2}$ capture on polyethylenimine in future investigations. As an illustrating example, the $\mathrm{CO}_{2}$ adsorption-desorption isotherms were measured at $298 \mathrm{~K}$ and $308 \mathrm{~K}$ at low pressure (1 bar) using a Model Belsorp Max instrument (BEL Japan, Inc.). A volumetric measurement method was used to obtain the $\mathrm{CO}_{2}$ adsorption capacity. Before measurement, the samples were degassed for $10 \mathrm{~h}$ at $200^{\circ} \mathrm{C}$ until the residual pressure fell below $0.01 \mathrm{kPa}$ and then cooled to room temperature. Photocatalytic activities of the as-prepared samples were estimated by the degradation rate of $\mathrm{RhB}$ under a Solar Simulator (Sun 2000, ABET) with a $440 \mathrm{~nm}$ cutoff filter (Figures 6 and 7).

To predict $\mathrm{CO}_{2}$ footprints beneath "nanodeserts," first we establish a mathematical equation to describe the dynamics of $\mathrm{CO}_{2}$ in the groundwater-soil system beneath hypothetically built "nanodeserts." Suppose that $\mathrm{CO}_{2}$ absorption per squaremeter alkaline soils was finally dissolved in the groundwater 
of volume $V$. Let $D_{0}$ be the initial amount of DIC at $t_{0}$ and the growth rate of DIC is $r$. Ignoring groundwater flows and the restricting effect of current DIC, it is straight that

$$
\frac{d D_{1}(t)}{d t}=D_{0} \cdot r\left(t-t_{0}\right)
$$

where $D_{1}(t)$ represents the one-dimension groundwater DIC dynamics.

Noting that $D_{1}(0)=D_{0}$, the analytic solution of (2) is $D_{1}(t)=D_{0} \cdot e^{r\left(t-t_{0}\right)}$.

Now take into account groundwater flows. It is natural to provide that outflow $=$ inflow, with volume $Q$. Because such flows are very slow, assume that groundwater flows out after the inflow is uniformly mixed with the groundwater unit $V$. The quality conversation law implies

$$
\begin{aligned}
D_{2}(t+\Delta t)-D_{2}(t)= & Q p \Delta t \\
& +\int_{t}^{t+\Delta t} r D_{2}(t)-Q \frac{D_{2}(t)}{V+Q} d t,
\end{aligned}
$$

where $p$ is DIC proportion in the inflows (hypothesized as a constant).

Simplifying and taking the limit $\Delta t \rightarrow 0$, it implies

$$
\frac{d D_{2}(t)}{d t}=Q p-\left(\frac{Q}{V+Q}-r\right) D_{2}(t) .
$$

Noting that $D_{2}(0)=D_{0}$, the analytic solution of $(2)$ is

$$
\begin{aligned}
D_{2}(t)= & \frac{Q p(V+Q)}{Q-r(V+Q)} \\
& -\left(D_{0}-\frac{Q p(V+Q)}{Q-r(V+Q)}\right) e^{(r-Q /(V+Q)) t},
\end{aligned}
$$

where $D_{2}(t)$ represents the two-dimension groundwater DIC dynamics.

Finally take into account both the groundwater flows and the restricting effect of current DIC. The quality conversation law implies

$$
\begin{aligned}
D_{3}(t & +\Delta t)-D_{3}(t) \\
= & Q p \Delta t \\
& \quad+\int_{t}^{t+\Delta t} r\left(R-\lambda D_{3}(t)\right) D_{3}(t)-Q \frac{D_{3}(t)}{V+Q} d t,
\end{aligned}
$$

where $R-\lambda D_{3}(t)$ determines the restricting effect of current DIC on $r$.

Simplifying and taking the limit $\Delta t \rightarrow 0$, it implies

$$
\frac{d D_{3}(t)}{d t}=Q p+\frac{r R(V+Q)-Q}{V+Q} D_{3}(t)-\lambda r D_{3}(t)^{2}
$$

where $D_{3}(t)$ represents the three-dimension groundwater DIC dynamics.

Equation (7) is the famous Riccati Equation, where the parameters $p, Q, r, R$, and $V$ are allowed to be changing with $t$ [15-18]. Equations (2) and (4) are both simple forms of (7) and hence are also special forms of the famous Riccati Equation. Generally the Riccati Equation has no analytic solutions unless some assumptions are imposed. And it is better to provide a specific example to prove analytic solutions in certain conditions, which help to understand the full story of $\mathrm{CO}_{2}$ footprint and make chances for the subsequent quantitative analysis of quasi-photosynthetic $\mathrm{CO}_{2}$ absorption and fixation beneath nanodeserts (Figure 8).

Suppose its analytic solutions by discussing that root of

$$
Q p+\frac{r R(V+Q)-Q}{V+Q} D_{3}(t)-\lambda r D_{3}(t)^{2}=0
$$

is zero; that is, $4 \lambda r p Q^{2}+(4 \lambda r p V+r R-1) Q+r R V$ is zero; then (8) has two same real roots, say $d$, and (7) is simplified as

$$
\frac{d D_{3}(t)}{\left(D_{3}(t)-d\right)^{2}}=\lambda r d t
$$

where the analytic solution can be obtained by $D_{3}(0)=D_{0}$ and

$$
D_{3}(t)=d-\frac{\lambda r}{t+c}, \quad c \text { is arbitrary constant. }
$$

$\mathrm{CO}_{2}$ footprints beneath nanodeserts can be therefore theoretically characterized. First, to note the auxiliary role of soil-groundwater metal ions in the $\mathrm{CO}_{2}$ footprints beneath nanodeserts is significant, which prepare chemical condition for the quasi-photosynthetic $\mathrm{CO}_{2}$ absorption beneath deserts (Figure 8). This is a key point of the whole story. Those metal ions come from the dissolution of soil salt during the discharge and recharge of groundwater. The percentages of those metal ions beneath deserts can be very different in different sites and the local extremes amount to $80 \mathrm{mg} / \mathrm{L}$ [47-56]. Second, the $\mathrm{CO}_{2}$ movements in the soil-groundwater system beneath nanodeserts are usually accompanied by the movements and sequestration of these metal ions. Finally, such accompanied movements present advantageous conditions for geochemical processes and therefore reconstruct $\mathrm{CO}_{2}$ footprints beneath nanodeserts. The above assumption and analytic solution (10) indicate that the quasi-photosynthetic $\mathrm{CO}_{2}$ absorption beneath deserts significantly contributed to the dynamic of the soil-groundwater $\mathrm{CO}_{2}$ concentration beneath deserts. In other words, the subterranean $C$ pool and $\mathrm{CO}_{2}$ footprints would be reconstructed in next centuries when/if the quasi-photosynthetic $\mathrm{CO}_{2}$ absorption becoming the predominant processes was beneath "nanodeserts."

\section{Discussion}

In subsequent studies, the diverse kinds of hierarchical structured nanoporous materials should be synthesized as a set of microporous nanomaterials with small pore size and their $\mathrm{CO}_{2}$ sorption performance should be mechanically analyzed. The performance of $\mathrm{CO}_{2}$ absorption by the hierarchical structured polymeric nanomaterials needs to be systematically investigated to find the critical pore size to enhance the $\mathrm{CO}_{2}$ uptake according to the arithmetic method 


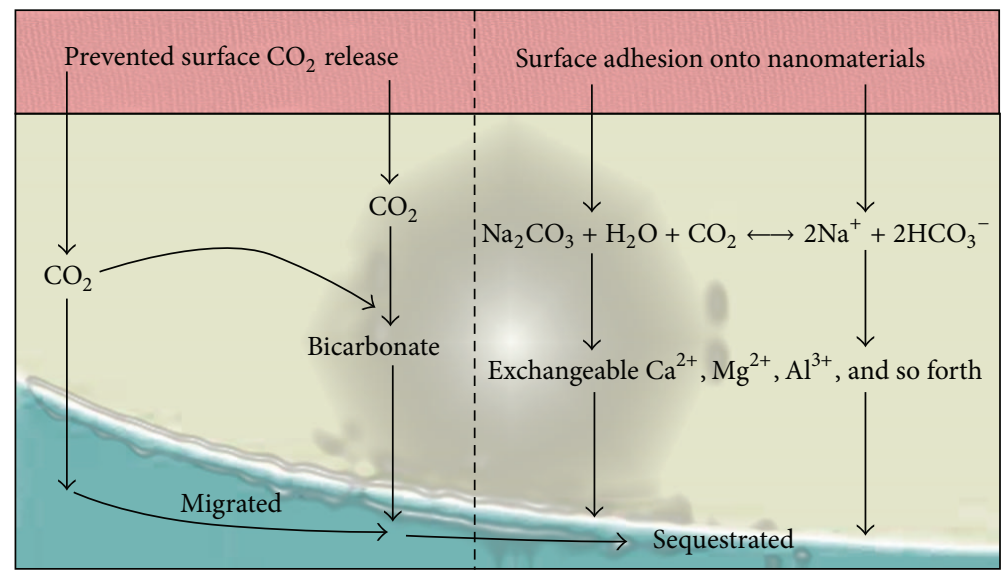

FIgURE 8: Hypothetical $\mathrm{CO}_{2}$ footprints beneath nanodeserts and the $\mathrm{C}$ sink kinetics in $\mathrm{CO}_{2}$ explosion.

proposed in subsequent studies. Moreover, the exact mechanisms about the heterostructured nanofibers for visible-light photocatalytic enhancements and full utilization of the solar thermal sources above nanodeserts are also worthy of further investigations [57-60].

In the present study it is indicated that it is the micropores with pore size smaller than a necessary pore size for soil $\mathrm{CO}_{2}$ release that play a crucial role in such abiotic $\mathrm{CO}_{2}$ adsorption. Such efforts are practical considering the wide applications of the hierarchical structured polymers and the nanomaterials. The pore structure and surface chemical properties of these prepared nanomaterials should be symmetrically studied by using different kinds of testing methods. Additionally, the DLS was used to measure the size of the nanoparticles in the present study since the size of the nanoparticles had been decorated on the PEI fibers. Considering the size of the particles is important for photocatalytic performance [61], it is very important to employ the DLS to measure the size distribution of the nanoparticles. Nevertheless, when measuring the diameter or the length of the PEI nanofiber, other suitable methods must be additionally employed since it is not appropriate to use DLS to measure such size of the fiber.

At the current stage it is impossible to obtain a reliable quantification of the $\mathrm{CO}_{2}$ adsorption capacity, but a preliminary approach can be concluded from Figures 6 and 7. One can get detailed information from Figures 6 and 7 , respectively. In Figure 6, it is highlighted that chemisorption of $\mathrm{CO}_{2}$ via amine-based solid adsorbents is another efficient approach to reduce the greenhouse gas emission [62]. In particular, polyethylenimine (PEI) impregnated materials exhibit superior adsorption selectivity, high adsorption capacity, water tolerance, and low energy consumption with respect to physisorption, holding great promise for $\mathrm{CO}_{2}$ capture [63]. Nevertheless, the low thermal conductivity of PEI coupled with high adsorption heat $(\Delta H)$ of chemisorption commonly generates overheating of these adsorbents during the $\mathrm{CO}_{2}$ capture. This unavoidably leads to partial degradation of PEI, poor cycle stability, and even safety problems. Therefore, the development of a suitable material with high $\mathrm{CO}_{2}$ adsorption capacity, superior adsorption selectivity, and excellent cycle performance remains a major challenge. In Figure 6, the GO sheets can serve as an efficient carrier support for PEI via a nanocasting technology. Such features are favorable for the efficient diffusion and adsorption of $\mathrm{CO}_{2}$ as well as the rapid thermal transfer. As for Figure 7, PEI nanofibers were prepared by electrospinning so that the graphene oxide/ $\mathrm{BiOCl}$ heterostructured $\mathrm{PEI}$ nanofibers can be synthesized through in situ method. As well known, harmful chemical compounds have become the main cause of water pollution. For instance, organic dyes are often discharged with wastewater into the local environment without adequate treatment. Although the preparation of graphene-based composite hydrogels for photocatalyst has been previously reported $[64,65]$, recovering the photocatalyst after waste water purification has been a challenging issue. Thus, polymer-based photocatalyst nanocomposites have been attracting more interest due to their advantages for photocatalyst recovery. Exactly, the formation of graphene oxide/ $\mathrm{BiOCl}$ heterostructured PEI nanofibers using an in situ reduction approach has been stated in the present study. Interestingly, this composite hydrogel matrix can be further utilized as highly efficient catalyst for wastewater treatment.

Furthermore, the Riccati Equation presented in the present studies demands further investigations by the mathematicians who are interested in this conjecture and are able to make contributions. Therefore, the analysis of qualitative properties of solutions to Riccati Equation is crucial for understanding the $\mathrm{CO}_{2}$ absorption, offering some cautionary notes for interpretations based on first principles for $\mathrm{CO}_{2}$ capture at ecosystem level and large-scale applications, which is also a future research priority.

\section{Conclusion}

"Nanodeserts" as a reconciled concept not only indicate a conjecture in nanotechnology to enhance quasiphotosynthetic $\mathrm{CO}_{2}$ absorption, but also aim to present to desert researchers a better understanding of the footprints of abiotic $\mathrm{CO}_{2}$ transport, conversion, and assignment in 
the soil-groundwater system beneath deserts. Meanwhile, nanodeserts allow a stable temperature sensitivity of soil respiration in deserts by largely reducing the $\mathrm{CO}_{2}$ release above the deserts surface and highlight the abiotic $\mathrm{CO}_{2}$ fixation beneath deserts. When/if the dream is realized, it is not difficult then to widely utilize the quasi-photosynthetic $\mathrm{CO}_{2}$ absorption in the soil-groundwater system and present further explicit modeling results towards a reliable quantification of the quasi-photosynthetic $\mathrm{CO}_{2}$ absorption beneath nanodeserts. This may be no longer a novelty in the future since deserts are attracting more and more interest in the increasingly urbanized world.

\section{Competing Interests}

The authors declared that there are no competing interests.

\section{Acknowledgments}

This work was financially supported by the National Natural Science Foundation of China (41571299), the "Thousand Talents" Plan (Y474161), the CAS "Light of West China" Program (XBBS-2014-16), and the Shenzhen ICSTI Basic Research Project (JCYJ 20150630114942260). Essential geodata were collected from National Science \& Technology Infrastructure Center-Data Sharing Infrastructure of Earth System Science (http://www.geodata.cn/).

\section{References}

[1] R. P. Detwiler and C. A. S. Hall, "Tropical forests and the global carbon cycle," Science, vol. 239, no. 4835, pp. 42-47, 1988.

[2] P. P. Tans, I. Y. Fung, and T. Takahashi, "Observational constraints on the global atmospheric $\mathrm{CO}_{2}$ budget," Science, vol. 247, no. 4949, pp. 1431-1438, 1990.

[3] R. F. Keeling, S. C. Piper, and M. Heimann, "Global and hemispheric $\mathrm{CO}_{2}$ sinks deduced from changes in atmospheric $\mathrm{O}_{2}$ concentration," Nature, vol. 381, no. 6579, pp. 218-221, 1996.

[4] D. W. Schindler, “The mysterious missing sink," Nature, vol. 398, no. 6723 , pp. 105-107, 1999.

[5] S. C. Wofsy, "Where has all the carbon gone?" Science, vol. 292, no. 5525, pp. 2261-2263, 2001.

[6] W. Wang, X. Chen, H. Zhang, C. Jing, Y. Zhang, and B. Yan, "Highlighting photocatalytic $\mathrm{H}_{2}$-production from natural seawater and the utilization of quasi-photosynthetic absorption as two ultimate solutions for $\mathrm{CO}_{2}$ mitigation," International Journal of Photoenergy, vol. 2015, Article ID 481624, 11 pages, 2015.

[7] J. X. Xie, Y. Li, C. X. Zhai, C. H. Li, and Z. D. Lan, "CO absorption by alkaline soils and its implication to the global carbon cycle," Environmental Geology, vol. 56, no. 5, pp. 953961, 2009.

[8] E. L. Yates, A. M. Detweiler, L. T. Iraci et al., "Assessing the role of alkaline soils on the carbon cycle at a playa site," Environmental Earth Sciences, vol. 70, no. 3, pp. 1047-1056, 2013.

[9] Y. Li, Y.-G. Wang, R. A. Houghton, and L.-S. Tang, "Hidden carbon sink beneath desert," Geophysical Research Letters, vol. 42, no. 14, pp. 5880-5887, 2015.

[10] J. Ma, Z.-Y. Wang, B. A. Stevenson, X.-J. Zheng, and Y. Li, "An inorganic $\mathrm{CO}_{2}$ diffusion and dissolution process explains negative $\mathrm{CO}_{2}$ fluxes in saline/alkaline soils," Scientific Reports, vol. 3, article 2025, 2013.

[11] X. Chen and W. F. Wang, "On the apparent $\mathrm{CO}_{2}$ absorption by alkaline soils," Biogeosciences Discussions, vol. 11, no. 2, pp. 2665-2683, 2014.

[12] X. Chen, W. F. Wang, G. P. Luo, and H. Ye, "Can soil respiration estimate neglect the contribution of abiotic exchange?" Journal of Arid Land, vol. 6, no. 2, pp. 129-135, 2014.

[13] X. Chen, W.-F. Wang, G.-P. Luo, L.-H. Li, and Y. Li, “Time lag between carbon dioxide influx to and efflux from bare salinealkali soil detected by the explicit partitioning and reconciling of soil $\mathrm{CO}_{2}$ flux," Stochastic Environmental Research and Risk Assessment, vol. 27, no. 3, pp. 737-745, 2013.

[14] W. H. Schlesinger, J. Belnap, and G. Marion, "On carbon sequestration in desert ecosystems," Global Change Biology, vol. 15, no. 6, pp. 1488-1490, 2009.

[15] B.-F. Kou and Q.-Z. Liu, "Wetting behavior of hydrophobic dust and dust-fall theory of fine droplets," Brazilian Journal of Physics, vol. 45, no. 6, pp. 708-712, 2015.

[16] C. Zhao, W. M. Ding, F. Chen, C. Cheng, and Q. J. Shao, "Effects of compositional changes of AFEX-treated and $\mathrm{H}$ AFEX-treated corn stover on enzymatic digestibility," Bioresource Technology, vol. 155, no. 3, pp. 34-40, 2014.

[17] Q. Feng, S. Li, X. Han, and S. Wang, "Network simulation for formation impairment due to suspended particles in injected water," Journal of Petroleum Science and Engineering, vol. 133, pp. 384-391, 2015.

[18] J. Tan, S. Wang, J. Yang, and Y. Liu, "Coupled particulate and continuum model for nanoparticle targeted delivery," Computers and Structures, vol. 122, pp. 128-134, 2013.

[19] V. A. Laudicina, A. Novara, L. Gristina, and L. Badalucco, "Soil carbon dynamics as affected by long-term contrasting cropping systems and tillages under semiarid Mediterranean climate," Applied Soil Ecology, vol. 73, pp. 140-147, 2014.

[20] Y. G. Su, L. Wu, Z. B. Zhou, Y. B. Liu, and Y. M. Zhang, "Carbon flux in deserts depends on soil cover type: a case study in the Gurbantunggute desert, North China," Soil Biology \& Biochemistry, vol. 58, pp. 332-340, 2013.

[21] Y. Wang, Z. Wang, and Y. Li, "Storage/turnover rate of inorganic carbon and its dissolvable part in the profile of saline/alkaline soils," PLoS ONE, vol. 8, no. 11, article e82029, 2013.

[22] J. Huang, Z. J. Gao, J. Chen, H. Zhang, and B. C. Xu, "Diurnal and seasonal variations of soil respiration rate under different row-spacing in a Panicum virgatum L. field on semi-arid Loess Plateau of China," Journal of Arid Land, vol. 8, no. 3, pp. 341-349, 2016.

[23] X. Gong, "Controlling surface properties of polyelectrolyte multilayers by assembly pH," Physical Chemistry Chemical Physics, vol. 15, no. 25, pp. 10459-10465, 2013.

[24] M. Zhang, F. Yang, S. Pasupuleti et al., "Preventing adhesion of Escherichia coli O157: H7 and Salmonella Typhimurium LT2 on tomato surfaces via ultrathin polyethylene glycol film," International Journal of Food Microbiology, vol. 185, pp. 73-81, 2014.

[25] W. F. Wang, X. Chen, G. P. Luo, and L. H. Li, "Modeling the contribution of abiotic exchange to $\mathrm{CO}_{2}$ flux in alkaline soils of arid areas," Journal of Arid Land, vol. 6, no. 1, pp. 27-36, 2014.

[26] R. Stone, "Have desert researchers discovered a hidden loop in the carbon cycle?" Science, vol. 320, no. 5882, pp. 1409-1410, 2008 . 
[27] J. Lloyd and J. A. Taylor, "On the temperature dependence of soil respiration," Functional Ecology, vol. 8, no. 3, pp. 315-323, 1994.

[28] N. Y. Kapustin and K. B. Sabitov, "The role of the Riccati equation in the theory of transonic gas dynamic flows," Matematicheskoe Modelirovanie, vol. 2, no. 9, pp. 105-113, 1990.

[29] B. Yan, P. S. Zhou, Q. Xu, X. F. Zhou, D. D. Xu, and J. H. $\mathrm{Zhu}$, "Engineering disorder into exotic electronic $2 \mathrm{D} \mathrm{TiO}_{2}$ nanosheets for enhanced photocatalytic performance," RSC Advances, vol. 6, no. 8, pp. 6133-6137, 2016.

[30] Y. L. Liu, Q. J. Guo, S. Q. Wang, and W. Hu, "Electrokinetic effects on detection time of nanowire biosensor," Applied Physics Letters, vol. 100, no. 15, Article ID 153502, 2012.

[31] S. Wang, Y. Wan, and Y. Liu, "Effects of nanopillar array diameter and spacing on cancer cell capture and cell behaviors," Nanoscale, vol. 6, no. 21, pp. 12482-12489, 2014.

[32] H. Dong, B. Lin, K. Gilmore, T. Hou, S.-T. Lee, and Y. Li, "B ${ }_{40}$ fullerene: an efficient material for $\mathrm{CO}_{2}$ capture, storage and separation," Current Applied Physics, vol. 15, no. 9, pp. 10841089, 2015.

[33] N. N. A. H. Meis, J. H. Bitter, and K. P. D. Jong, "Support and size effects of activated hydrotalcites for precombustion $\mathrm{CO}_{2}$ capture," Industrial \& Engineering Chemistry Research, vol. 49, no. 3, pp. 1229-1235, 2010.

[34] I. Ganesh, "Electrochemical conversion of carbon dioxide into renewable fuel chemicals - the role of nanomaterials and the commercialization," Renewable and Sustainable Energy Reviews, vol. 59, pp. 1269-1297, 2016.

[35] F. Atalay, "Synthesis of $\mathrm{NiO}$ nanostructures using Cladosporium cladosporioides fungi for energy storage applications," Nanomaterials and Nanotechnology, vol. 6, no. 28, pp. 1-6, 2016.

[36] L. K. Pan, "Editorial: functional semiconductor nanomaterials for renewable energy conversion and storage," Current Nanoscience, vol. 12, no. 3, pp. 316-316, 2016.

[37] A. Mirzabaev, M. Ahmed, J. Werner, J. Pender, and M. Louhaichi, "Rangelands of Central Asia: challenges and opportunities," Journal of Arid Land, vol. 8, no. 1, pp. 93-108, 2016.

[38] N. B. Grimm, S. H. Faeth, N. E. Golubiewski et al., "Global change and the ecology of cities," Science, vol. 319, no. 5864, pp. 756-760, 2008.

[39] H. Wan, C. Huang, and J. Pang, "Major elements in the Holocene loess-paleosol sequence in the upper reaches of the Weihe River valley, China," Journal of Arid Land, vol. 8, no. 2, pp. 197-206, 2016.

[40] H. Sohrabi, S. Bakhtiarvand-Bakhtiari, and K. Ahmadi, "Aboveand below-ground biomass and carbon stocks of different tree plantations in central Iran," Journal of Arid Land, vol. 8, no. 1, pp. 138-145, 2016.

[41] J. Ruokolainen, G. Ten Brinke, and O. Ikkala, "Supramolecular polymeric materials with hierarchical structure-withinstructure morphologies," Advanced Materials, vol. 11, no. 9, pp. 777-780, 1999.

[42] E. Baer, A. Hiltner, and H. D. Keith, "Hierarchical structure in polymeric materials," Science, vol. 235, no. 4792, pp. 1015-1022, 1987.

[43] Y. Cui, A. T. Paxson, K. M. Smyth, and K. K. Varanasi, "Hierarchical polymeric textures via solvent-induced phase transformation: a single-step production of large-area superhydrophobic surfaces," Colloids and Surfaces A: Physicochemical and Engineering Aspects, vol. 394, pp. 8-13, 2012.
[44] Y. Yoon, D. Kim, and J. B. Lee, "Hierarchical micro/nano structures for super-hydrophobic surfaces and super-lyophobic surface against liquid metal," Micro \& Nano Systems Letters, vol. 2, no. 1, pp. 1-18, 2014.

[45] J. W. Lee, C. Lee, S. Y. Choi, and S. H. Kim, "Block copolymersurfactant complexes in thin films for multiple usages from hierarchical structure to nano-objects," Macromolecules, vol. 43, no. 1, pp. 442-447, 2010.

[46] R. Akbarzadeh, J. A. Minton, C. S. Janney, T. A. Smith, P. F. James, and A.-M. Yousefi, "Hierarchical polymeric scaffolds support the growth of $\mathrm{MC}_{3} \mathrm{~T}_{3}-\mathrm{E}_{1}$ cells," Journal of Materials Science: Materials in Medicine, vol. 26, no. 2, pp. 1-12, 2015.

[47] Y. Q. Cui, J. Y. Ma, and W. Sun, "Application of stable isotope techniques to the study of soil salinization," Journal of Arid Land, vol. 3, no. 4, pp. 285-291, 2011.

[48] S. Danierhan, A. Shalamu, H. Tumaerbai, and D. Guan, "Effects of emitter discharge rates on soil salinity distribution and cotton (Gossypium hirsutum L.) yield under drip irrigation with plastic mulch in an arid region of Northwest China," Journal of Arid Land, vol. 5, no. 1, pp. 51-59, 2013.

[49] L. T. Su, M. T. Yu, and Y. D. Song, "Effects of emitter discharge rate on soil salt dynamics in cotton field under drip irrigation with mulching condition in arid regions," Arid Land Geography, vol. 33, no. 6, pp. 889-895, 2010.

[50] I. Bahçec1, R. Çakir, A. S. Nacar, and P. Bahçecı, "Estimating the effect of controlled drainage on soil salinity and irrigation efficiency in the Harran Plain using SaltMod," Turkish Journal of Agriculture \& Forestry, vol. 32, no. 2, pp. 101-109, 2008.

[51] A. El-Keblawy, S. Gairola, and A. Bhatt, "Maternal salinity environment affects salt tolerance during germination in Anabasis setifera: a facultative desert halophyte," Journal of Arid Land, vol. 8, no. 2, pp. 254-263, 2016.

[52] X. Yang, A. Mamtimin, Q. He, X. Liu, and W. Huo, “Observation of saltation activity at Tazhong area in Taklimakan Desert, China," Journal of Arid Land, vol. 5, no. 1, pp. 32-41, 2013.

[53] W. Z. Zeng, C. Xu, J. W. Wu, and J. S. Huang, "Soil salt leaching under different irrigation regimes: HYDRUS-1D modelling and analysis," Journal of Arid Land, vol. 6, no. 1, pp. 44-58, 2014.

[54] L. J. Chen and Q. Feng, "Soil water and salt distribution under furrow irrigation of saline water with plastic mulch on ridge," Journal of Arid Land, vol. 5, no. 1, pp. 60-70, 2013.

[55] X. Zhao, H. Xu, P. Zhang, and Y. Bai, "Distribution of soil moisture and salinity in shelterbelts and its relationship with groundwater level in extreme arid area, northwest of China," Water and Environment Journal, vol. 27, no. 4, pp. 453-461, 2013.

[56] J. Abuduwaili, Y. Tang, M. Abulimiti, D. Liu, and L. Ma, "Spatial distribution of soil moisture, salinity and organic matter in Manas River watershed, Xinjiang, China," Journal of Arid Land, vol. 4, no. 4, pp. 441-449, 2012.

[57] Y. Zhang, S. Liu, Z. Xiu, Q. Lu, H. Sun, and G. Liu, “ $\mathrm{TiO}_{2} / \mathrm{BiOI}$ heterostructured nanofibers: electrospinning-solvothermal two-step synthesis and visible-light photocatalytic performance investigation," Journal of Nanoparticle Research, vol. 16, no. 5, article 2375, pp. 1-9, 2014.

[58] L.-H. Xie and M. P. Suh, "High $\mathrm{CO}_{2}$-capture ability of a porous organic polymer bifunctionalized with carboxy and triazole groups," Chemistry, vol. 19, no. 35, pp. 11590-11597, 2013.

[59] H. Nakamoto and H. Tsutsumi, "Electrospun sulfur fibers as a template for micrometer-sized copper sulfide tubes," Materials Letters, vol. 136, no. 12, pp. 26-29, 2014. 
[60] L. Persano, A. Camposeo, and D. Pisignano, "Active polymer nanofibers for photonics, electronics, energy generation and micromechanics," Progress in Polymer Science, vol. 43, article 895, pp. 48-95, 2015.

[61] C. Aprile, A. Corma, and H. Garcia, "Enhancement of the photocatalytic activity of $\mathrm{TiO}_{2}$ through spatial structuring and particle size control: from subnanometric to submillimetric length scale," Physical Chemistry Chemical Physics, vol. 10, no. 6, pp. 769-783, 2008.

[62] J. C. Hicks, J. H. Drese, D. J. Fauth, M. L. Gray, G. G. Qi, and C. W. Jones, "Designing adsorbents for $\mathrm{CO}_{2}$ capture from flue gas-hyperbranched aminosilicas capable of capturing $\mathrm{CO}_{2}$ reversibly," Journal of the American Chemical Society, vol. 130, no. 10, pp. 2902-2903, 2008.

[63] X. L. Ma, X. X. Wang, and C. S. Song, "'Molecular basket' sorbents for separation of $\mathrm{CO}_{2}$ and $\mathrm{H}_{2} \mathrm{~S}$ from various gas streams," Journal of the American Chemical Society, vol. 131, no. 16, pp. 5777-5783, 2009.

[64] W. J. Han, L. Ren, L. Gong et al., "Self-assembled threedimensional graphene-based aerogel with embedded multifarious functional nanoparticles and its excellent photoelectrochemical activities," ACS Sustainable Chemistry \& Engineering, vol. 2, no. 4, pp. 741-748, 2014.

[65] Y.-E. Moon, G. Jung, J. Yun, and H.-I. Kim, "Poly(vinyl alcohol)/poly(acrylic acid)/ $/ \mathrm{TiO}_{2} /$ graphene oxide nanocomposite hydrogels for $\mathrm{pH}$-sensitive photocatalytic degradation of organic pollutants," Materials Science and Engineering B: SolidState Materials for Advanced Technology, vol. 178, no. 17, pp. 1097-1103, 2013. 

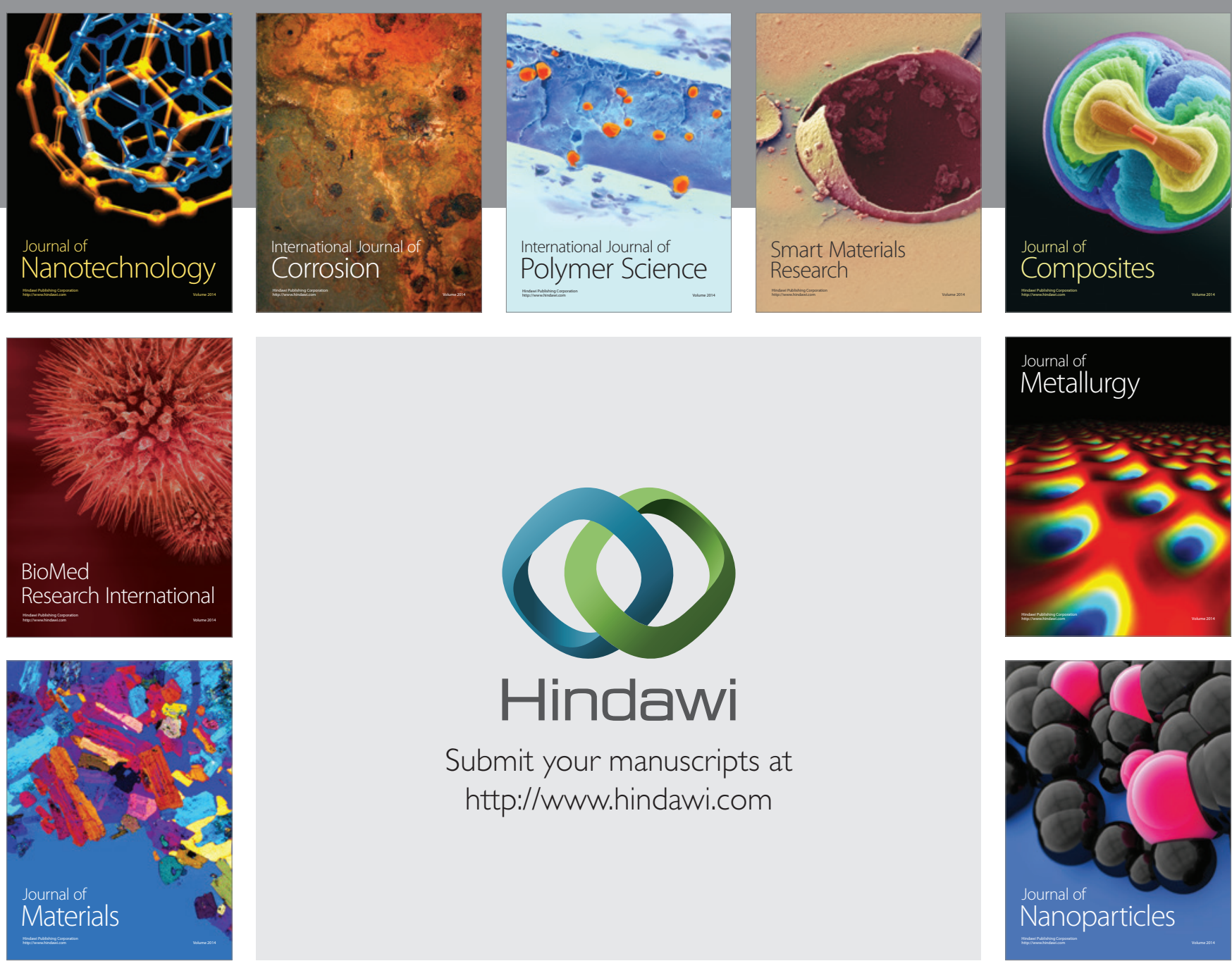

\section{Hindawi}

Submit your manuscripts at

http://www.hindawi.com

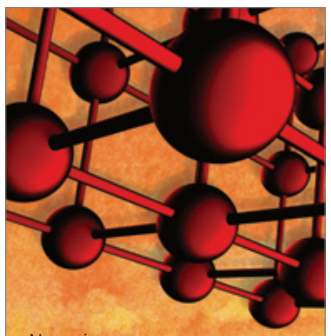

Materials Science and Engineering
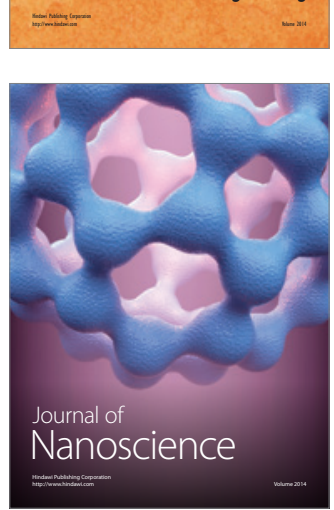
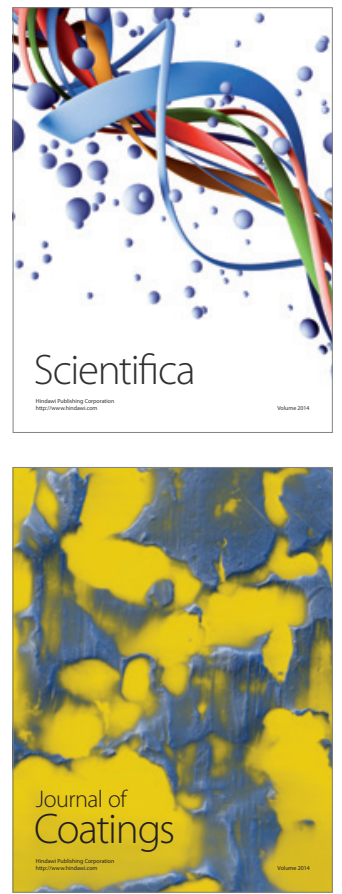
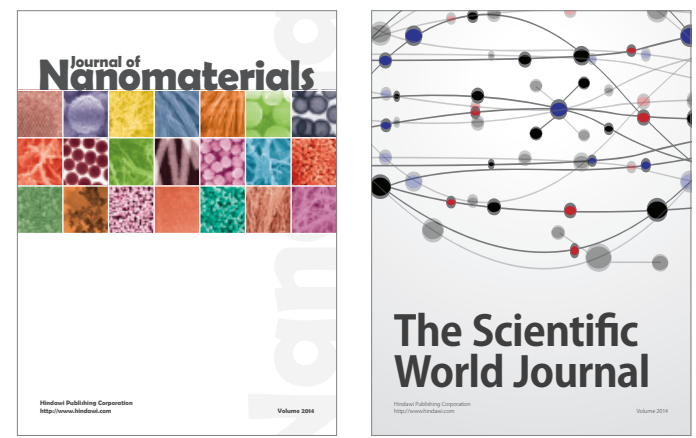

The Scientific World Journal
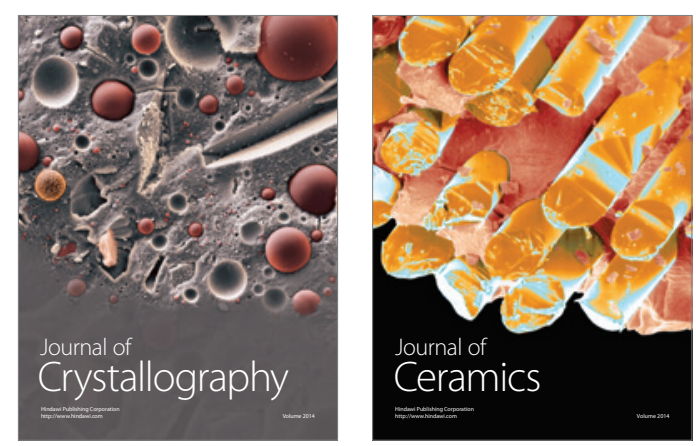
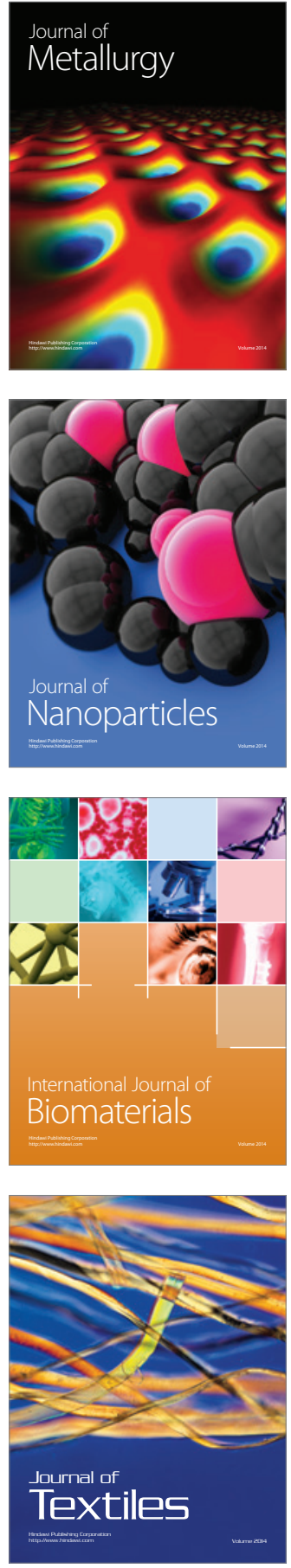